\title{
About influence of non-sinusoidal currents and voltages on the amount of the electric energy
}

\author{
Valery Vanin ${ }^{1}$, Alexandr Bulychov ${ }^{1}$, Maxim Popov ${ }^{1}$, Olga Vasilyeva, ,* and Maria \\ Shakhova ${ }^{1}$ \\ ${ }^{1}$ Peter the Great St. Petersburg Polytechnic University, Polytechnicheskaya 29, St. Petersburg, \\ 195251, Russian Federation.
}

\begin{abstract}
The results of measurements of the harmonics components of the current, voltage, power of harmonics at the point of connection of electric receivers with a non-linear voltage-current characteristic are considered. It is shown that the amount of electric energy including the non-sinusoidality of the currents and voltages consumed by the non-linear load is less than the amount of the fundamental frequency energy. The difference between them is the harmonic distortion energy that causes extra losses to the electric networks. The voltage harmonic distortions at the measurement point exceed the normative values for $0.4 \mathrm{kV}$ electric networks.
\end{abstract}

\section{Introduction}

A common violation of the quality of electric energy is the non-sinusoidal nature of currents and voltages. This is confirmed by the results of measurements of the power quality indices (PQI) in the electric networks of Russia, published in the sources [1-3]. Non-sinusoidality of currents and voltages can lead to a change in operating modes and a shortening of the service life of electrical equipment, failures in the work of relay protection and emergency automatics, an increase in accidents in consumer networks [4-8].

The non-sinusoidal current and voltage influence on the amount of electrical energy consumed. An electric receiver with a non-linear current-voltage characteristic, consuming the fundamental frequency energy, returns to the network its part in the form of harmonic components energy - the distortion energy, which reduces the reliability of the metering of electric energy used in economic calculations. The issues of the influence of electric power characteristics on the metering of the electric energy amount are considered in works by other authors [9-11].

The aim of the research is to evaluate the influence of higher harmonics of current generated by electric receivers with a non-linear voltage-current characteristic on the electric energy amount consumed by them. The object of research is $0.4 \mathrm{kV}$ feeder bay with a computer and luminescent lighting load.

Objectives of the research:

\footnotetext{
* Corresponding author: vasilieva_oa@spbstu.ru
} 
1) measurement and analysis of the spectrum of higher harmonics of current, voltage, power at the point of connection of the consumer with a computer and luminescent lighting load;

2) metering of the amount of the fundamental frequency energy, positive sequence energy, energy including the non-sinusoidality and unbalance of currents and voltages, and an estimate of the harmonic distortion energy amount;

3) conformity assessment of the voltage harmonic distortions to the standard values established for $0.4 \mathrm{kV}$ networks [12].

\section{Methods and Results}

The measurements were performed using a BINOM3 series device (type BINOM337U3.22013.5S16T2). The device is certified for compliance with the power meters requirements (accuracy class $0.2 \mathrm{~s}$ ) and to devices for power quality indices measurement (class A, class accuracy I) [12 - 17], measures the extended list of power quality indices [18].

The form of the voltage and the current consumed at the measurement point (Fig. 1) differs from the sinusoidal. The odd harmonics of the $3,5,7,9,11,13$ and $15^{\text {th }}$-orders are expressed in the current and voltage harmonic distortions spectrums (Fig. 2).

In the power harmonics spectrum (Fig. 3), the power of the fundamental frequency current and voltage in each phase is positive (directed from the network to the consumer), and the power of the higher harmonics is negative (directed from the consumer to the network). The sample for the predominant harmonics in phase A is given in Table 1. The third-order harmonic parameters are of greatest value.

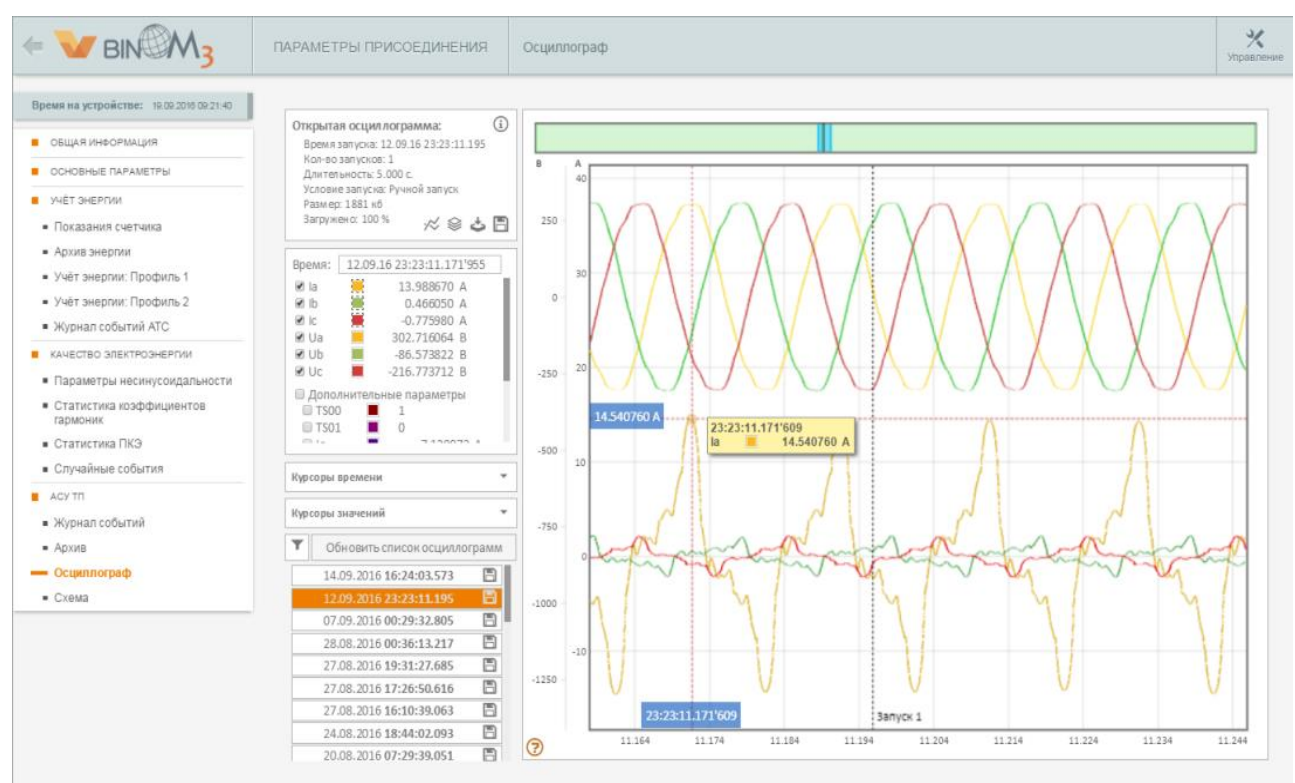

Figure 1. Phase Voltage and Current Waveform. 


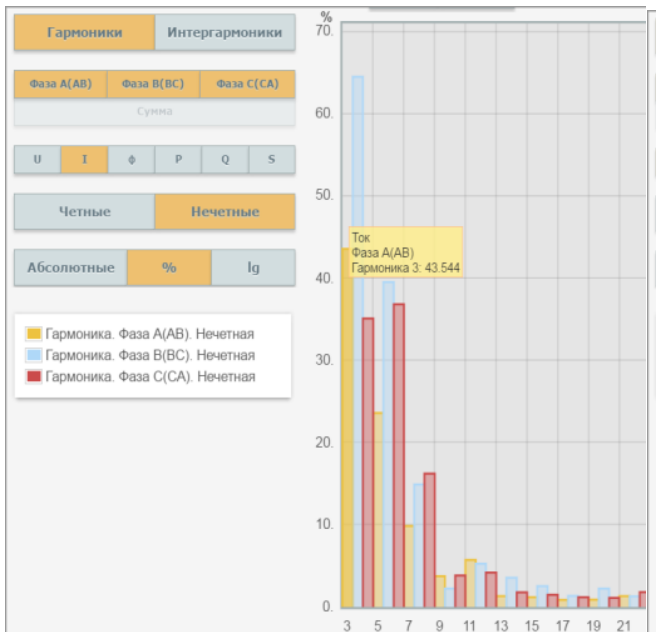

(a) Spectrum of current harmonic distortions $\mathrm{K}_{\mathrm{I}}$ (n) $=I_{(n)} / I_{1}, \%$

Figure 2. Spectrums of odd order current and voltage harmonic distortions. RMS values, 3 phases: A, $\mathrm{B}, \mathrm{C}$ (from left to right).

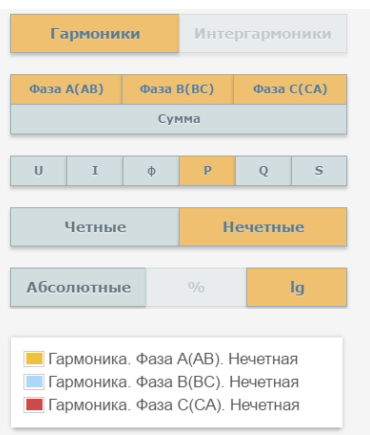

Figure 3. The power odd order harmonics spectrum $P_{(n)}$, W. RMS values, 3 phases: $A, B, C$ (from left to right), logarithmic scale.

Table 1. RMS values of current, voltage and power harmonics in phase A for the spectrum of Fig. 2, 3.

\begin{tabular}{|c|c|c|c|c|c|}
\hline \multirow{2}{*}{$\begin{array}{c}\text { Harmonic } \\
\text { order }\end{array}$} & \multicolumn{2}{|c|}{$\mathrm{U}_{(\mathrm{n}) \mathrm{A}}$} & \multicolumn{2}{c|}{$\mathrm{I}_{(\mathrm{n}) \mathrm{A}}$} & $\mathrm{P}_{(\mathrm{n}) \mathrm{A}}$ \\
\cline { 2 - 6 } & $\mathrm{V}$ & $\%$ & $\mathrm{~A}$ & $\%$ & $\mathrm{~W}$ \\
\hline 1 & $\mathbf{2 1 7 . 6 5 3}$ & $\mathbf{1 0 0 . 0 0 0}$ & $\mathbf{7 . 3 2 9 5 8}$ & $\mathbf{1 0 0 . 0 0 0}$ & $\mathbf{1 5 5 5 . 7 1 4}$ \\
\hline 3 & $\mathbf{1 2 . 4 7 1}$ & $\mathbf{5 . 7 2 8}$ & $\mathbf{3 . 2 3 4 5 2}$ & $\mathbf{4 3 . 5 4 4}$ & $\mathbf{- 2 1 . 1 7 6}$ \\
\hline 5 & 2.689 & 1.218 & 1.75371 & 23.601 & -1.140 \\
\hline 7 & 2.934 & 1.377 & 0.69482 & 9.763 & -0.130 \\
\hline 9 & 1.269 & 0.611 & 0.29987 & 3.886 & -0.029 \\
\hline 11 & 0.730 & 0.367 & 0.40788 & 5.596 & 0.117 \\
\hline 13 & 0.531 & 0.254 & 0.10470 & 1.338 & -0.055 \\
\hline 15 & 0.282 & 0.120 & 0.08776 & 1.205 & -0.019 \\
\hline
\end{tabular}


According to the definition for active power for periodic non-sinusoidal currents (for simplicity, the interharmonic components are not considered), we have:

$$
\begin{gathered}
P_{\Sigma}=\sum_{n=1}^{n=\infty} P_{(n)}=P_{1}+P_{2}+\cdots+P_{(n)}+\cdots=U_{1} I_{1} \cos \varphi_{1}+U_{2} I_{2} \cos \varphi_{2}+\cdots+ \\
U_{(n)} I_{(n)} \cos \varphi_{(n)}
\end{gathered}
$$

where $U_{(n)}$ - RMS value of the n-order voltage harmonic,

$I_{(n)}-R M S$ value of the n-order current harmonic,

$\cos \varphi_{(\mathrm{n})}$ - the phase shift angle between the n-order current and voltage harmonics,

$P_{(n)}$ - the active power of n-order current and voltage harmonics.

In this case, the resulting active power in phase A, including all frequencies (up to order 50), $\mathrm{P}_{\Sigma}$, is $1533.273 \mathrm{~W}$, which is less than the active power value of the fundamental frequency $\mathrm{P}_{1}$ equal to $1555.14 \mathrm{~W}$ (Table 1). Thus, it is shown that at the non-linear consumer connection point the power contains negative harmonics directed from the consumer to the network. This negative harmonics power reduces the value of the positive fundamental frequency power coming from the network to the consumer.

The same holds for energy. The active energy of three-phase feeder bay is the integral value for the time of active power in phases. On the histograms of daily and monthly consumption (Fig. 4 and 5) the amount of energy including harmonics and unbalance - "+ Wa Total" is compared with the amount of the fundamental frequency energy "+ Wah1 Total".

For each time interval (day, month), the value of the energy including harmonics and unbalance is less than the fundamental frequency energy value. For example, on September 12,2016 , the fundamental frequency energy value was $45.386 \mathrm{kWh}$, the value of the energy including harmonics and unbalance was $44.944 \mathrm{kWh}$, the difference in values $-0.442 \mathrm{kWh}$ ( $0.97 \%$ of the fundamental frequency energy).

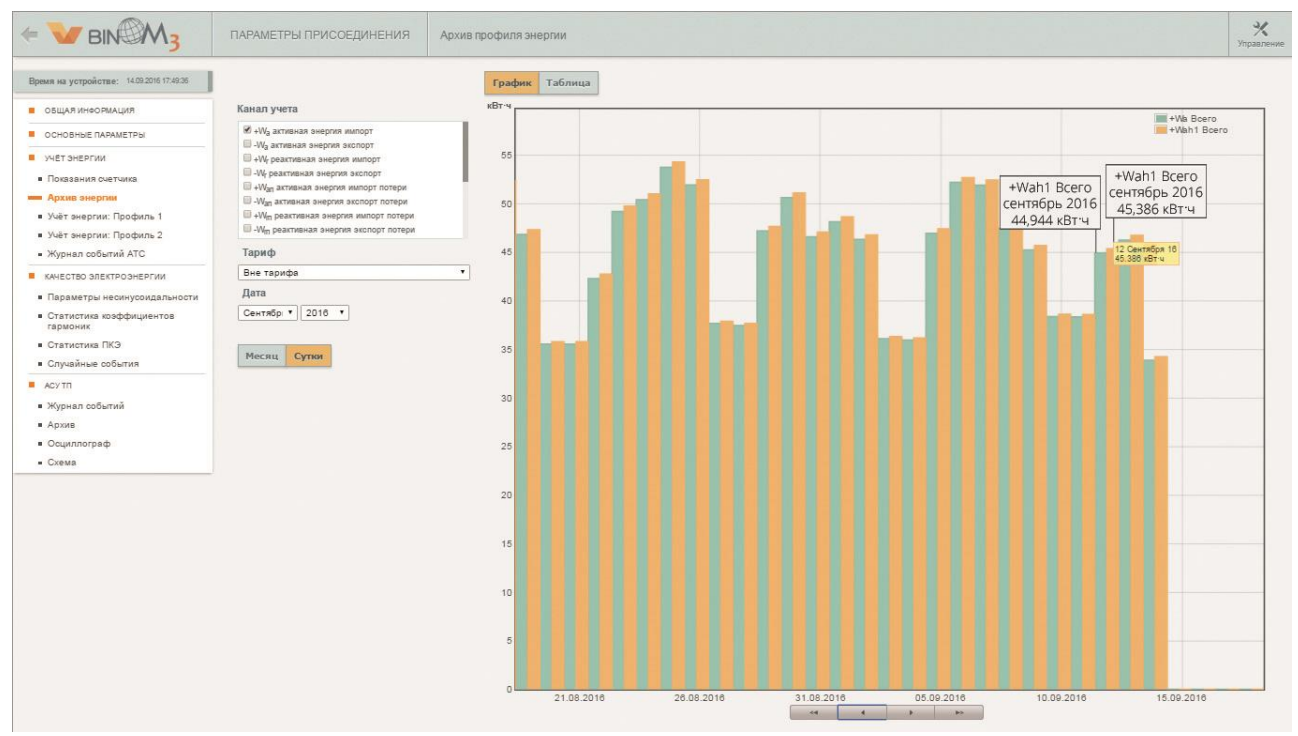

Figure 4. Daily energy consumption histogram (metering channels: fundamental frequency active energy, active energy including harmonics and unbalance). 


\section{EECE-2018}

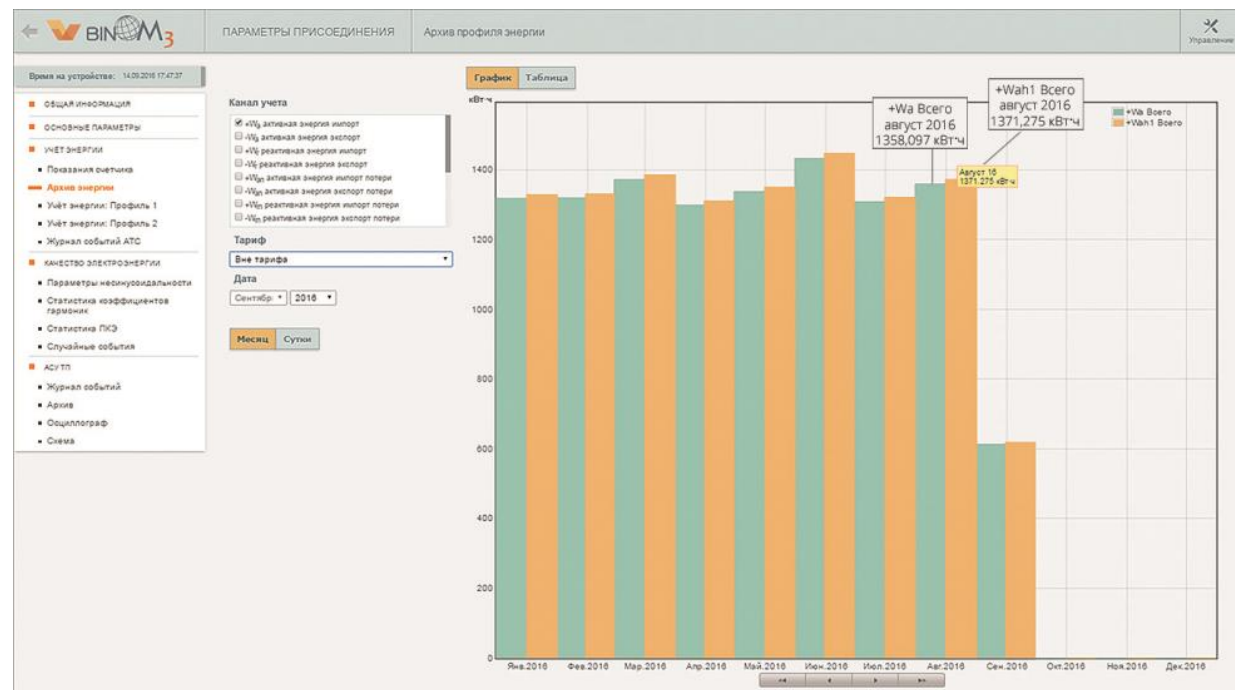

Figure 5. Monthly energy consumption histogram (metering channels: fundamental frequency active energy, active energy including harmonics and unbalance).

The difference in the values of the fundamental frequency energy and energy including harmonics and unbalance, represents the harmonic distortion energy $\mathrm{W}_{\mathrm{h} . \text { dist }}$, caused by the negative power of the harmonics directed from the consumer with a non-linear load to the supply network, which practically confirms the theoretical provisions on the effect of the electric power characteristics on the amount of the electric energy, stated in $[9,19]$.

For unbalance and non-linear loads, the distortion energy may contain two components: due to non-sinusoidality and due to unbalance. Table 2 shows the data on electric energy consumption metering in three accounting channels by months from the beginning of the year.

In each month, the active energy including harmonics and unbalance "+ Wa", is less than fundamental frequency active energy "+ Wah1", which is less than the positive sequence active energy "+ Wad".

Table 2. Active energy parameters.

\begin{tabular}{|c|c|c|c|c|c|}
\hline Time & $\begin{array}{l}+\mathrm{Wa} \\
\mathrm{kWh}\end{array}$ & $\begin{array}{c}+ \text { Wah } 1 \\
\text { kWh }\end{array}$ & $\begin{array}{l}+\mathrm{Wad} \\
\mathrm{kWh}\end{array}$ & $\begin{aligned} &(+\mathrm{Wad}- \\
&+\mathrm{Wa}), \mathrm{kWh}\end{aligned}$ & $\begin{array}{c}(+\mathrm{Wad}- \\
+\mathrm{Wa}) /+\mathrm{Wad}, \%\end{array}$ \\
\hline January & 1316.904 & 1328.351 & 1331.860 & 14.956 & $1.12 \%$ \\
\hline February & 1318.242 & 1329.943 & 1334.375 & 16.133 & $1.21 \%$ \\
\hline March & 1371.341 & 1384.504 & 1389.288 & 17.947 & $1.29 \%$ \\
\hline April & 1297.703 & 1310.168 & 1317.308 & 19.605 & $1.49 \%$ \\
\hline May & 1336.379 & 1349.405 & 1354.277 & 17.898 & $1.32 \%$ \\
\hline June & 1431.716 & 1446.793 & 1449.881 & 18.165 & $1.25 \%$ \\
\hline July & 1307.645 & 1320.591 & 1324.308 & 16.663 & $1.26 \%$ \\
\hline August & 1358.097 & 1371.275 & 1374.852 & 16.755 & $1.22 \%$ \\
\hline $\begin{array}{l}\text { TOTAL } \\
2016\end{array}$ & 10738.027 & 10841.031 & 10876.149 & 138.122 & $1.27 \%$ \\
\hline \multicolumn{6}{|c|}{$\begin{array}{l}\text { +Wa - active energy including harmonics and unbalance } \\
\text { +Wah1 - fundamental frequencyactive energy } \\
\text { +Wad - fundamental frequencyactive energy of the positive sequence (positive } \\
\text { sequenceactive energy) }\end{array}$} \\
\hline
\end{tabular}


The results of the PQI statistical processing show that in all observation periods values of the 3, 9 and $15^{\text {th }}$-order voltage harmonics are exceeded their rated permitted values (Fig. $6)$.

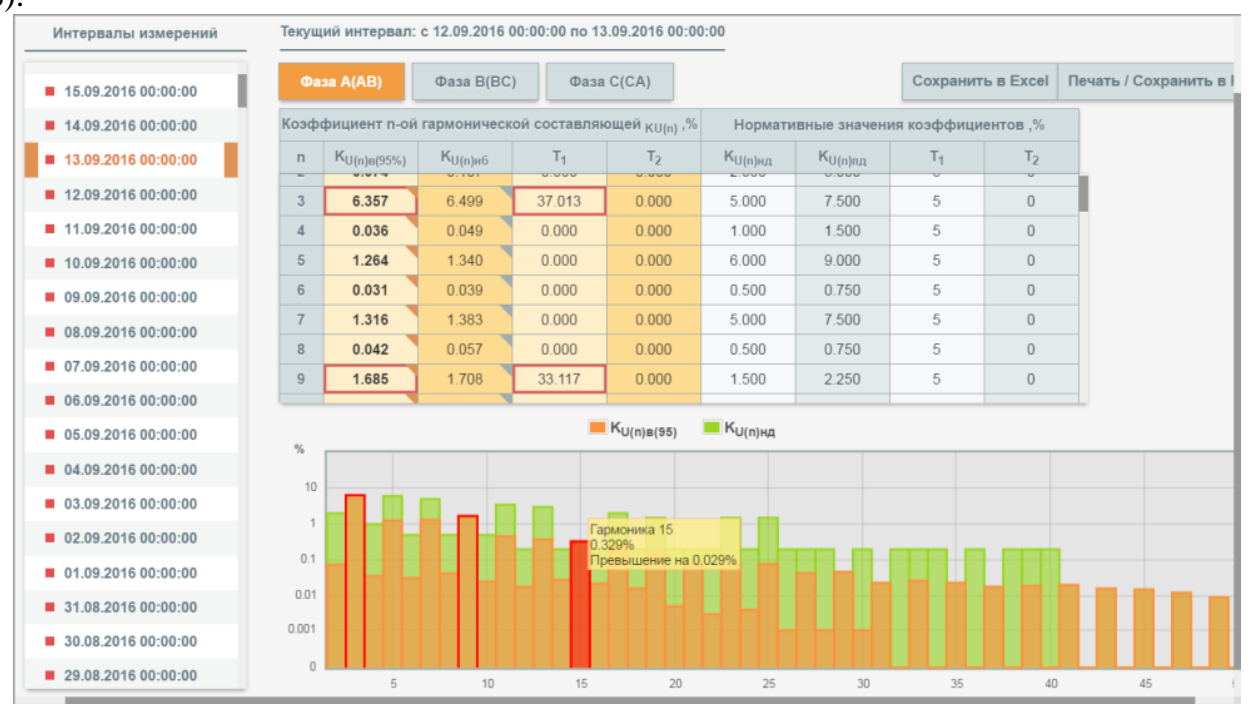

Figure 6. Voltage harmonic distortion statistics. Values averaged over a 10-minutes time intervals.

The frequencies at which the normative values of the voltage harmonics are violated are present in the spectrums of the current and power consumed (directed from the consumer to the network), which may indicate the contribution made by this consumer to the distortion of the of electrical energy quality by voltage.It is worth noting that in foreign standards the values of current harmonics are normalized, for example, [20].

For self-acquaintance with the presented results and other measurements, on-line access to the device is opened at http://www.binom3.com/.

\section{Conclusions}

1. The results of measurements confirm that characteristic harmonics of $3,5,7,9,11$, 13 and $15^{\text {th }}$-orders prevail in the current and voltage spectrum at the point of connection of a consumer with a computer and luminescent lighting load. The power spectrum contains negative harmonic power, which is directed from the consumer to the network and reduces the value of the fundamental frequency positive power coming from the network to the consumer.

2. It has been experimentally shown that the amount of electric energy including nonsinusoidal and unbalanced current and voltage consumed by the non-linear load is less than the amount of the fundamental frequency electric energy, which practically confirms the effect of the electric energy characteristics on the amount of electric energy.

3. The voltage harmonic distortions at the measurement point exceed the standard values established for $0.4 \mathrm{kV}$ networks, which is caused by the actual influence of the nonlinear consumer receivers.

\section{References}

1. L.I. Kovernikova, V.N. Tulsky, R.G. Shamonov. Electricity. Transmission and distribution, 2 (35), 40-50 (2016) 
2. V.S. Borovikov, M.V. Volkov, V.V. Ivanov, V.V. Litvak, V.A. Melnikov, A.I. Pogonin, N.N. Harlow. Experience of corporate survey of electrical networks of $110 \mathrm{kV}$ of Siberia. Tomsk (2010)

3. V.S. Borovikov, M.V. Volkov, V.V. Ivanov, V.V. Litvak, V.A. Melnikov, A.I. Pogonin, N.N. Kharlov, T.B. Akimzhanov, Regime properties of $110 \mathrm{kV}$ electric networks in the south of Russia in ensuring the efficiency of electric power transmission. Tomsk (2013)

4. V.N. Gromov, Proc. of the Int. Scientific and Practical Conf.: Power Quality Management, 85-93 (2014)

5. O.A. Vasilyeva, Automation and IT in the energy sector, 12 (77), 27-34 (2015)

6. O.A. Vasilyeva, The 8th Sientific and Technical Conf.: Metrology. Accounting and quality control of electrical energy. Measurements in intelligent networks, 153 (2016)

7. V.N. Tulsky, I.I. Kartashov, M.G. Simutkin, R.R. Nasyrov. Industrial Energy, 5, 42-47 (2013)

8. M.G. Simutkin. V.N. Tulsky. Proceedings of the International Scientific and Practical Conference: Power Quality Management, 161-171 (2014)

9. O.V. Bolshakov. Automation and IT in the energy sector, 16 (65) (2014)

10. O.V. Bolshakov, A.N. Krasnova. Proceedings of the International Scientific and Practical Conference: Power Quality Management, $45-53$ (2014)

11. V.V. Kiselev, I.S. Ponomarenko. Industrial Energy, 2 (2004)

12. GOST 32144-2013. Electric energy. Power quality limits in the public power supply systems. (2014)

13. GOST 31819.22-2012 (IEC 62053-22:2003). Electricity metering equipment (a.c). Particular requirements. Part 22. Static meters for active energy (classes 0,2S and $0,5 S)$. (2014)

14.GOST 30804.4.30-2013 (IEC 61000-4-30:2008). Electric energy. Power quality measurement methods. (2014)

15.GOST 30804.4.7-2013 (IEC 61000-4-7:2009). General guide on harmonics and interharmonics measuring instruments and measurement, for power supply systems and equipment connected thereto. (2014)

16. GOST $R$ 8.655-2009. State system for ensuring the uniformity of measurements. Quality factors of electric power measuring instruments. General technical requirements. (2010)

17.GOST 33073-2014. Electric energy. Electromagnetic compatibility of technical equipment. Control and monitoring of electric power quality in the public power supply systems. (2015)

18. Methodology (measurement method) for an extended list of Power Quality Indicators", JSC "Firm ORGRES" Att. №010-01 / 00032-2013, FR.1.34.2014.17965

19. O.V. Bolshakov, OA Vasilyeva, Automation and IT in the energy sector, 11 (88), 2837 (2016)

20. IEEE 519-1992.IEEE Recommended Practicesand Requirements for Harmonic Control in Electrical Power Systems. (1993) 